\title{
Modeling of Effects of Temperature and Alloying Elements on Austenite Phase Growth Rate in Duplex Stainless Steel
}

\author{
Kazuhiro OGAWA* and Akira SEKI \\ Nippon Steel Corporation, 1-8 Fuso-cho, Amagasaki, Hyogo, 660-0891 Japan. \\ (Received on December 27, 2018; accepted on February 26, 2019)
}

\begin{abstract}
The growth rate of austenite phase from overcooled ferrite phase in duplex stainless steel was investigated to clarify the quantitative effects of temperature and chemistry in isothermal heating process. The proper fraction of ferrite and austenite phase is very important to obtain the maximum performance such as toughness and corrosion resistance of the steels. However, the fraction in heat affected zone (HAZ) in weldments can be changed during welding process.

A physical model of growth rate as function of temperature including the parameter regarding chemistries was suggested. The measurement of austenite phase conducted experimentally after isothermally heated at various temperature, employing $25 \% \mathrm{Cr}$ or $22 \% \mathrm{Cr}$ duplex stainless steels containing various level of nitrogen. Referring those data obtained, it was confirmed that the effects of temperature and chromium and nitrogen contents on the growth rate is explained by the physical model suggested in this work.
\end{abstract}

KEY WORDS: duplex stainless steel; austenite phase fraction; modeling; alloying element; growth rate; kinetics.

\section{Introduction}

Recently duplex stainless steels consisting of ferrite and austenite phase are widely used for various structural materials because of high performance for cost. The high performance in terms of mechanical property and corrosion resistance is obtained in the condition of approximately equal fraction of ferrite and austenite phase in the duplex stainless steel. Therefore the fraction of the phase is controlled in the optimum range during the manufacturing process including the heat treatment. However, in the welded portion it is indispensable to be heated at the high temperature where the phase transformation is remarkable, therefore the fraction of the phase can be changed out of the optimum range in heat affected zone (HAZ) by weld thermal cycles. The duplex stainless steel that does not change so much in microstructure even in HAZ has been continuously developed.

From that background many research works ${ }^{1-6)}$ have been conducted about the microstructure change in HAZ of duplex stainless steels. Those works were categorized as the following approaches. 1) the effects of $\mathrm{Ni}$ and $\mathrm{N}$ and cooling rate on the formation of austenite phase in HAZ cooled from high temperature where microstructure transforms toward mono phase of the ferrite. ${ }^{2)} 2$ ) the formation of austenite phase from the overcooled ferrite phase during the isothermal heating at the dual phase temperature range ${ }^{3,4)} 3$ ) the prediction of the austenite formation in the continuously cooled HAZ by using the data in the isothermal heating. ${ }^{4-6)}$ Concerning the modeling of austenite phase formation from

\footnotetext{
* Corresponding author: E-mail: ogawa.m3f.kazuhiro@jp.nipponsteel.com DOI: https://doi.org/10.2355/isijinternational.ISIJINT-2018-869
}

the overcooled ferrite phase in HAZ, the method of calculation to obtain the fraction of austenite phase by applying the additivity rule to the experimental growth rate data in isothermal heating has been established in those works. ${ }^{3-6)}$ In many works much of growth rate data of austenite phase have been obtained experimentally for the individual steels with of various chemical compositions but by using those data growth property have not been physically modeled as a function of temperature in isothermal heating and amount of alloying element. Consequently the applicability of the growth rate data for the steel consisting of other chemistry is not sufficient.

In this work the physical model to describe the effects of alloying elements and temperature on the growth rate of austenite phase from the overcooled ferrite phase was investigated.

\section{Experimental}

The duplex stainless steels containing chromium of $25 \%$ or $22 \%$ listed in Table 1 were used. Those were melted in laboratory, hot forged and hot rolled to $12 \mathrm{~mm}$ thick plates in the range of 1373 to $1523 \mathrm{~K}$ then those were heat treated by water quench after holding at $1373 \mathrm{~K}$ for $1800 \mathrm{~s}$. Those plates were machined to the specimens of $11 \mathrm{~mm}$ in thickness and $11 \mathrm{~mm}$ in width and $60 \mathrm{~mm}$ in length. The specimens were heated at $1653 \mathrm{~K}$ for $3 \mathrm{~s}$ and cooled rapidly with argon gas to the various test temperatures. And then those are held for various durations at a constant temperature and quenched with argon gas shower. The average cooling rate was approximately $100 \mathrm{~K} / \mathrm{s}$. To measure the initial fraction of austenite phase before holding at a constant temperature, 
Table 1. Chemical compositions of steels tested (mass $\%$ ).

\begin{tabular}{cccccccc}
\hline $\mathrm{C}$ & $\mathrm{Si}$ & $\mathrm{Mn}$ & $\mathrm{Ni}$ & $\mathrm{Cr}$ & $\mathrm{W}$ & $\mathrm{Mo}$ & $\mathrm{N}$ \\
\hline 0.02 & 0.17 & 0.47 & 7.11 & 25.20 & 1.95 & 2.97 & 0.33 \\
0.02 & 0.16 & 0.47 & 7.14 & 25.10 & 1.99 & 2.98 & 0.22 \\
0.02 & 0.16 & 0.48 & 7.10 & 25.29 & 1.98 & 3.03 & 0.11 \\
0.02 & 0.16 & 0.50 & 4.96 & 22.04 & - & 3.00 & 0.20 \\
0.02 & 0.16 & 0.46 & 4.96 & 22.00 & - & 3.01 & 0.09 \\
\hline
\end{tabular}

some specimens were quenched with argon gas shower from $1653 \mathrm{~K}$ to the room temperature.

The heat treated specimens were buff polished and used for the measurement of the fraction of austenite phase in the image field of the magnification of 100 using EBSD (Electron Back Scatter Diffraction) analysis. In addition in some of the specimens the amount of alloying elements was measured using EPMA(X-ray Probe Micro-Analyser).

\section{Modeling of Austenite Phase Growth}

The main items of modeling of austenite phase growth from over-cooled ferrite phased are the following.

1) The growth is according to the equation based on the impingement effect by Austin-Rickett rule, which has been clarified to be able to describe the transformation behavior of austenite from the over-cooled ferrite phase. ${ }^{3)}$

2) The growth is determined by diffusion.

3) The process of transformation is considered to consist of the two stages. In the stage I the growth progressing to the para-equilibrium is determined by the interstitial type element such as N. In the stage II the growth progressing to the ortho-equilibrium is determined by the substitution type element such as $\mathrm{Ni}$.

4) The shape of austenite phase is simplified as a disk growing just to the radius direction without growing of the thickness.

When the density of number of austenite phase is $N_{p}$, and the average radius and thickness of the disk are $r_{m}$ and $\mathrm{L}$ respectively, the growth of $r_{m}$ is described as the following equations in the condition of phase interface migration determined by diffusion with the flax balance and with the mass conservation using the linear gradient approximation ${ }^{7)}$ at the interface in the cylindrical coordinate system.

$$
\begin{aligned}
& r_{m}^{2}=2 D \varphi(\omega) t \\
& \omega=\left(C_{i}^{\infty}-C_{i}^{\alpha}\right) /\left(C_{i}^{\gamma}-C_{i}^{\alpha}\right)
\end{aligned}
$$

$C_{i}^{\infty}, C_{i}^{\alpha}, C_{i}^{\gamma}$ is the concentration of alloying element $\mathrm{i}$ at the phase interface as shown in Fig. 1, where suffix of $i$ means solute elements such as $\mathrm{Ni}, \mathrm{Cr}$, Mo and $\mathrm{W}$.

$$
\varphi(\omega)=2 \omega / 3\left(\sqrt{1+\frac{4}{3} \cdot \frac{1-\omega}{\omega}}-1\right)^{-1}
$$

When the whole volume is $V_{0}$, the extended volume of austenite phase $V_{e x}$ is described as the following.

$$
V_{e x}=V_{0} N_{p} \pi r_{m}^{2} \mathrm{~L}=2 V_{0} N_{p} \pi \mathrm{L} D \varphi(\omega) t
$$

When the number of austenite phase formation sites is according to Boltzmann distribution, the density of number

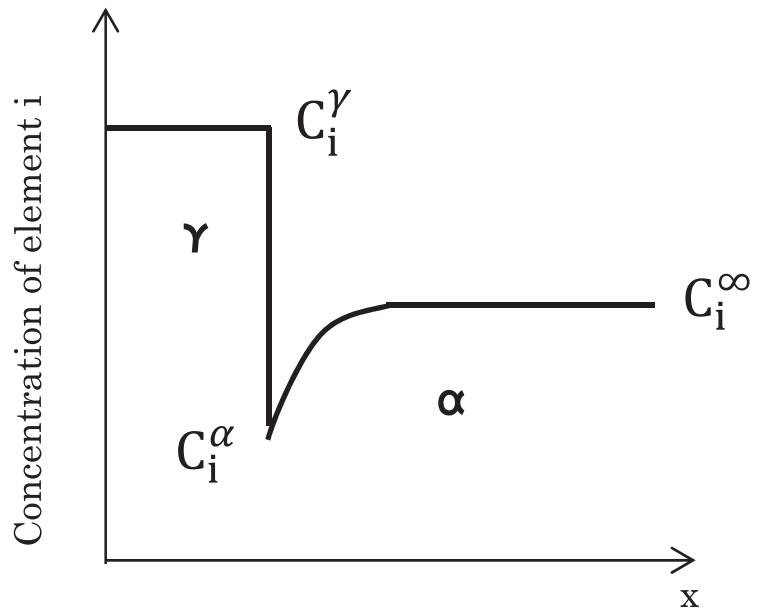

Fig. 1. Concentration of alloying element i $C_{i}^{\infty}, C_{i}^{\alpha}, C_{i}^{\gamma}$ in vicinity of $\alpha / \gamma$ phase interface.

of that phase $N_{p}$ is the following equation. ${ }^{8)}$

$$
N_{p}=N_{0} \exp \left(-\Delta u_{m}\left(T_{e q} / \Delta T\right)^{2} / R T\right) .
$$

Where $\mathrm{T}_{\mathrm{eq}}(\mathrm{K})$ is the upper limit temperature for the stability of austenite phase, $\Delta \mathrm{T}$ is equal to $\mathrm{T}_{e q}-T$ and $\Delta u_{m}\left(T_{e q} / \Delta T\right)^{2}$ is the term regarding the energy barrier in the transformation of ferrite to austenite phase. The value of $N_{0}$ is the maximum number of austenite phase formation sites and $\mathrm{R}$ is the gas constant.

Because the equilibrium volume of austenite $V_{p 0}$ should be equal to $\omega V_{0}$, the transformation ratio $\mathrm{X}=V_{e x} / V_{p 0}$ is equal to $V_{e x} / V_{0} / \omega$, where $\omega$ is the oversaturation for an element. Considering the effect of impingement by AustinRickett, the following equation is obtained.

$$
\mathrm{X} /(1-\mathrm{X})=2 \pi N_{p} L D \varphi(\omega) / \omega t=\left(k_{p} t\right)^{m}
$$

By comparing between the two right sides the result of $\mathrm{m}=1$ is determined.

Consequently the following equation describing the growth of austenite phase is obtained.

$$
\begin{aligned}
\mathrm{X} /(1-\mathrm{X}) & =2 \pi L D N_{0} \exp \left(-\Delta u_{m}\left(T_{e q} / \Delta T\right)^{2} / R T\right) \varphi(\omega) / \omega t \\
& =k_{p} t
\end{aligned}
$$

In the stage II the growth of austenite phase is determined by the diffusion of substitution type elements such as Ni. In the practical experimental process the growth by the diffusion of interstitial elements can have almost finished in the stage I, because the formation of austenite phase in the cooling process to test temperature from $1653 \mathrm{~K}$ is considered to occur even quenched with gas shower. Therefore experimental data of austenite phase growth was analyzed as transformation in stage II. The initial value of austenite phase fraction of each steel in the stage II was determined using experimental data of the specimens quenched with gas shower from $1653 \mathrm{~K}$ to room temperature, which reflect the formation of austenite phase by the diffusion of $\mathrm{N}$.

In this model it is assumed that the diffusion of $\mathrm{Ni}$ is the dominant for transformation and the dependence of value of $\varphi(\omega) / \omega$ regarding the diffusion of $\mathrm{Ni}$ on temperature is negligible in the temperature range away from $\mathrm{T}_{\text {eq }}$. The value of $\varphi(\omega) / \omega$ is described as constant value of $\Omega$. 


$$
\mathrm{X} /(1-\mathrm{X})=k_{p} \mathrm{t}=k_{p 0} \mathrm{D}_{N i} \exp \left(-\Delta u_{m}\left(T_{e q} / \Delta T\right)^{2} / R T\right) t
$$

$$
\text { where } k_{p 0}=2 \pi L \Omega N_{0}
$$

From the above equation theoretical value of the growth rate constant $k_{p}$ in this model is obtained at various temperatures for each of steels.

\section{Effect of Temperature and Alloying Elements on Growth of Austenite Phase}

The microstructure of the $25 \% \mathrm{Cr}-7 \% \mathrm{Ni}-3 \% \mathrm{Mo}-2 \% \mathrm{~W}$ $0.1 \% \mathrm{~N}$ steel held at $1173 \mathrm{~K}$ for $100 \mathrm{~s}$ after overcooled from $1653 \mathrm{~K}$ is shown in Fig. 2 as an example of experimental results. The results of EBSD analysis of that specimen are shown in Fig. 3, where the analyzed portion is not accurately same as the portion shown in Fig. 2. From this analysis the fraction of austenite phase was $31.1 \%$. By the same way the fractions of austenite phase $\mathrm{f}(\mathrm{t})$ were obtained in all the specimens of the steels treated with various heating conditions. Using those data of $\mathrm{f}(\mathrm{t})$, transformation ratio $\mathrm{X}$ and $\log (X /(1-X))$ were calculated with the following equations.

$$
\begin{aligned}
& \mathrm{X}=f(t) / f_{e} \\
& \mathrm{X} /(1-X)=f(t) /\left(f_{e}-f_{0}\right)-f_{0} /\left(f_{e}-f_{0}\right) .
\end{aligned}
$$
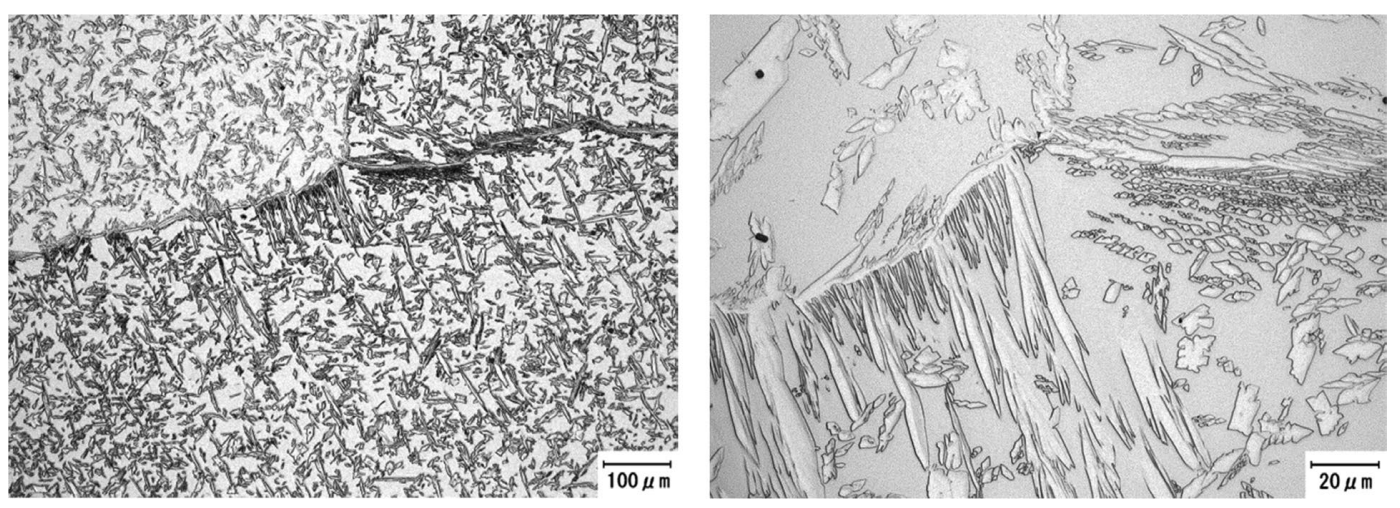

Fig. 2. Example of optical micrograph of $25 \mathrm{Cr}-7 \mathrm{Ni}-3 \mathrm{Mo}-2 \mathrm{~W}-0.2 \mathrm{~N}$ steel heated at $1173 \mathrm{~K}$ for $100 \mathrm{~s}$ after rapidly cooled from $1653 \mathrm{~K}$.

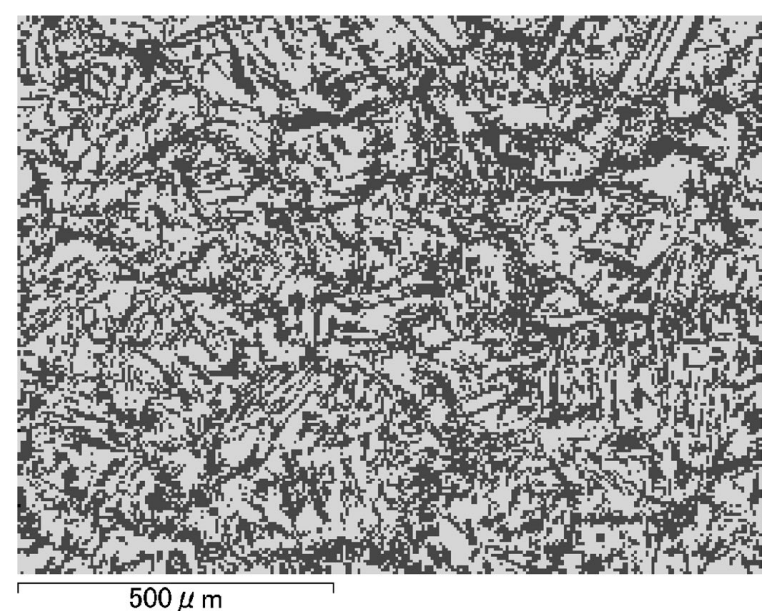

Fig. 3. Example of austenite phase detected as black area by EBSD analysis in 25Cr-7Ni-3Mo-2W-0.2N heated at 1173 $\mathrm{K}$ for $100 \mathrm{~s}$ after rapidly cooled from $1653 \mathrm{~K}$.
Where $f_{e}$ is the equilibrium fraction of austenite at a temperature and $f_{0}$ is the initial fraction of austenite phase in the time of $\mathrm{t}=0$. The values of $f_{e}$ shown in Fig. 4 are obtained by using the thermodynamic data $(2017 \mathrm{a} \text {, database:TCFe } 8)^{10)}$ and the value of $f_{0}$ is obtained by the measurement using gas quenched specimens from $1653 \mathrm{~K}$ shown in Table 2. The values of $T_{\text {eq }}$ are also obtained by using the thermodynamic data (2017a, database:TCFe8). ${ }^{10}$

Figure 5 shows the experimental results plotted against the logarithm of heating time $t$ according to Austin-Reckett manner. The value of $X /(1-X)$ increased almost proportionally to the logarithm of heating time with the inclination of

\begin{tabular}{|c|c|c|c|c|c|c|c|c|}
\hline $\mathrm{Cr}$ & $\mathrm{Ni}$ & $\mathrm{N}$ & other & $\begin{array}{c}\mathrm{k}_{\mathrm{p} 0} \\
\left(\mathrm{~m}^{-2}\right)\end{array}$ & $\underset{(\mathrm{J} / \mathrm{mol})}{\Delta \mathrm{u}_{\mathrm{m}}}$ & $\begin{array}{l}\mathrm{T}_{\mathrm{eq}} \\
(\mathrm{K})\end{array}$ & $\begin{array}{c}\mathrm{f}_{0} \\
(\%)\end{array}$ & \\
\hline 25 & 7 & 0.3 & $3 \mathrm{Mo}, 2 \mathrm{~W}$ & $4.0 \times 10^{14}$ & 1950 & 1668 & 50 & \multirow{5}{*}{$\begin{array}{l}\text { by this } \\
\text { work }\end{array}$} \\
\hline 25 & 7 & 0.2 & $3 \mathrm{Mo}, 2 \mathrm{~W}$ & $2.3 \times 10^{14}$ & 1950 & 1640 & 31 & \\
\hline 25 & 7 & 0.1 & $3 \mathrm{Mo}, 2 \mathrm{~W}$ & $1.1 \times 10^{14}$ & 1950 & 1618 & 0 & \\
\hline 22 & 5 & 0.2 & $3 \mathrm{Mo}$ & $3.3 \times 10^{14}$ & 1950 & 1656 & 35 & \\
\hline 22 & 5 & 0.1 & $3 \mathrm{Mo}$ & $1.1 \times 10^{14}$ & 1950 & 1610 & 6 & \\
\hline 25 & 5.4 & 0.07 & $1.8 \mathrm{Mo}$ & $8.5 \times 10^{14}$ & 1950 & 1640 & 0 & * \\
\hline
\end{tabular}
1.0. The results confirmed that the austenite phase growth occurred according to the Eq. (6) with $m=1$. The values

Table 2. Constant values used for growth rate constant $\mathrm{k}_{\mathrm{p}}$.

* by applying data of Nako's work to model of this work . 
of the intercept obtained from the linear relation of those experimental plots correspond to the growth rate constant $\mathrm{k}_{\mathrm{p}}$ in the Eq. (6). The obtained growth rate constants of $k_{p}$ are plotted against the invers of absolute temperature in the heating shown in Fig. 6. The growth rate constant had the maximum value for the heating temperature and that maximum value tends to be higher in the steel of the higher $T_{\text {eq }}$.

From the measured fractions of austenite phase the TimeTemperature-Precipitation curves were drawn as shown in Fig. 7 where the horizontal axis is the invers of absolute temperature. The criteria of TTP curve is $60 \%$ in fraction or
0.9 in transformation ratio respectively in the two figures. In the figure the inclinations between the logarithm of time and the invers of absolute temperature are drawn and those correspond to the value of $\mathrm{Q} / \mathrm{R}$, where the value of $\mathrm{Q}$ corresponding to the activation energy of diffusion of $\mathrm{Ni}$ and N, 242 and $83(\mathrm{~kJ} / \mathrm{mol})$ respectively is applied. In the low temperature range where the growth is determined by the diffusion, the incline of the part of TTP curve was close to Q/R of the activation energy of diffusion of $\mathrm{Ni}$. The fact supports that the dominant element for austenite phase growth is not $\mathrm{N}$ but $\mathrm{Ni}$.

The average contents of $\mathrm{Ni}$ in each phase with EPMA
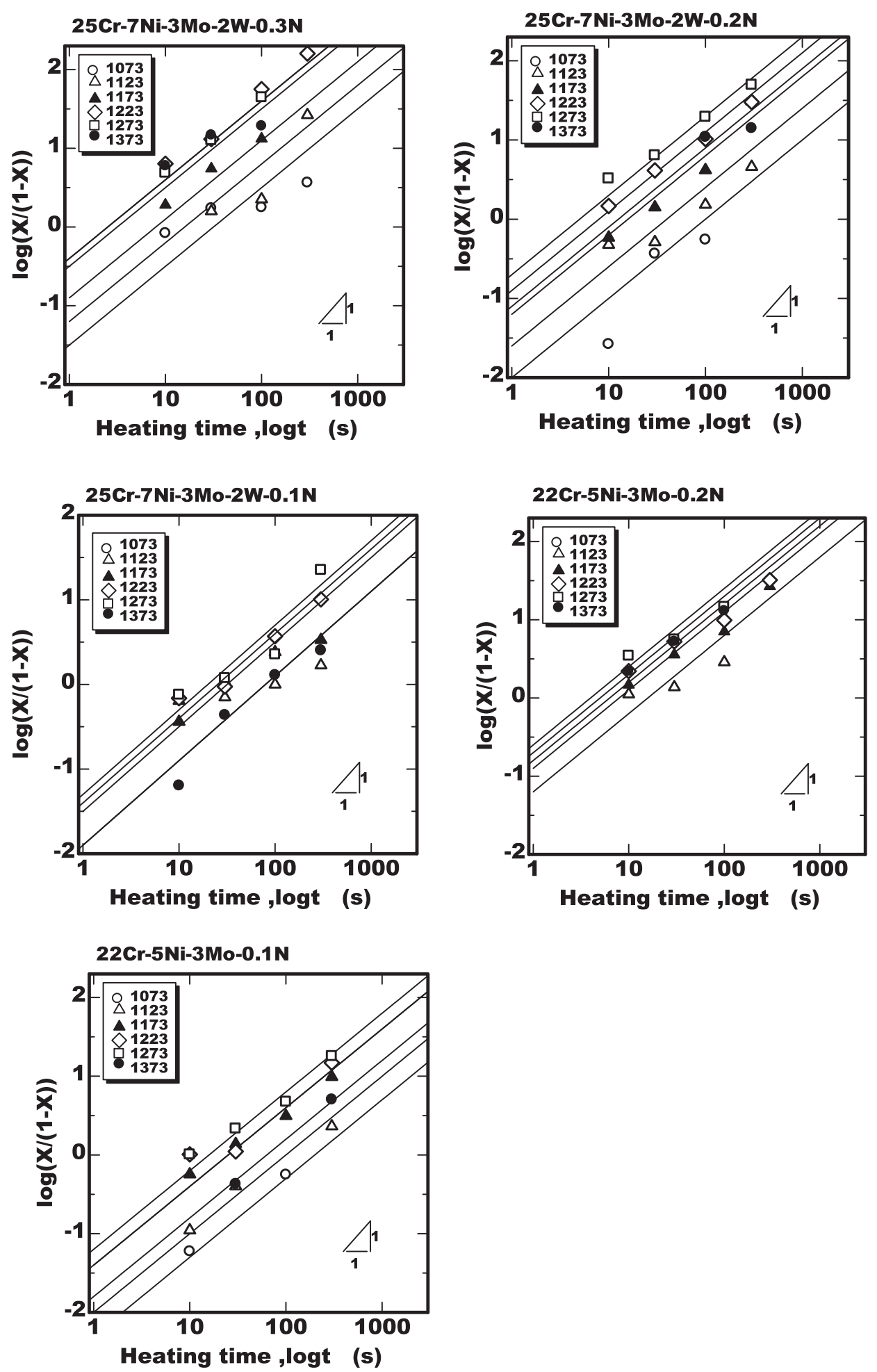

Fig. 5. Austin-Rikett plot of austenite phase precipitation from overcooled ferrite during isothermal heating. 


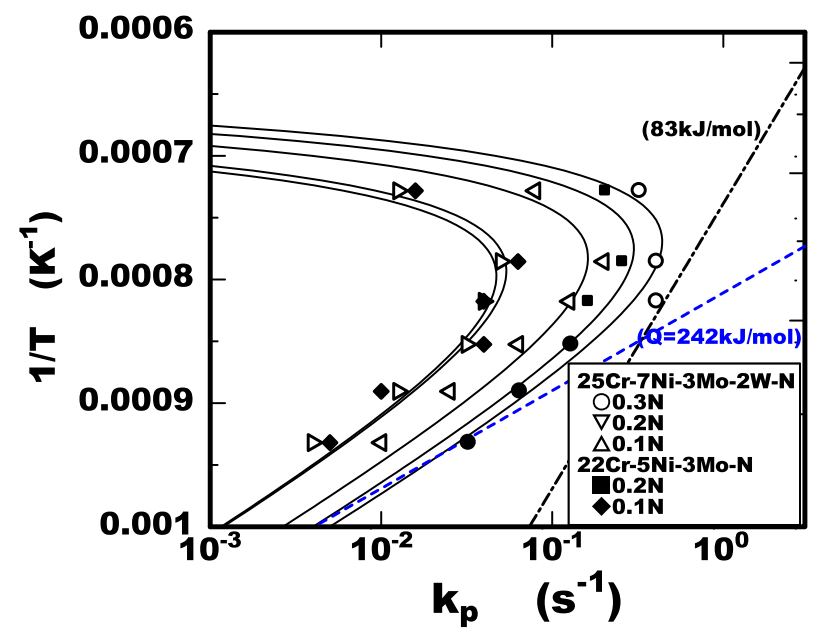

Fig. 6. Effect of temperature on growth rate constant of austenite phase from overcooled ferrite in $25 \mathrm{Cr}$ or $22 \mathrm{Cr}$ steel containing various levels of $\mathrm{Ni}$ and $\mathrm{N}$. (Online version in color.)

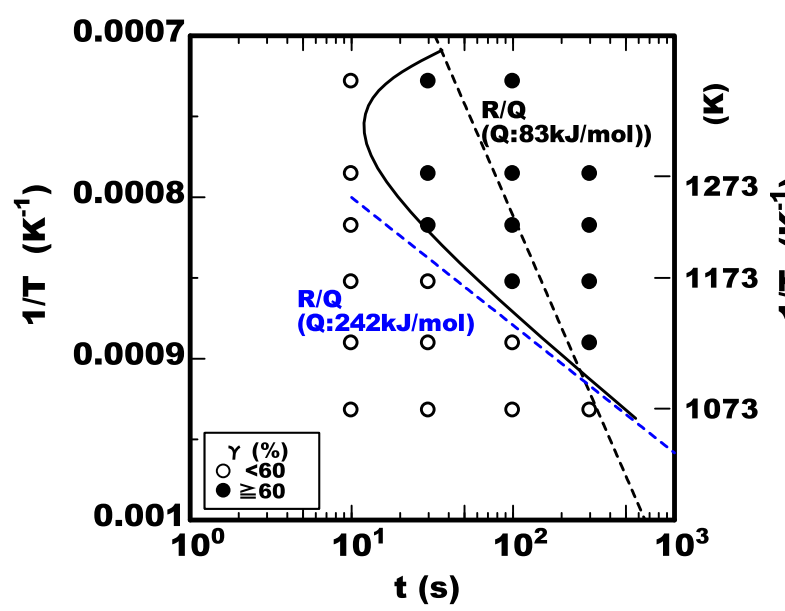

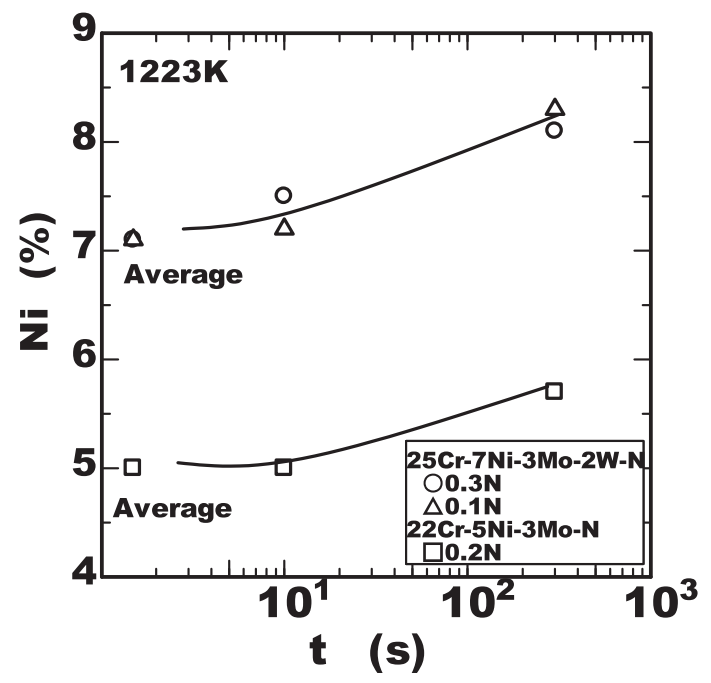

Fig. 8. Change of Ni content in austenite phase during heating at $1223 \mathrm{~K}$.

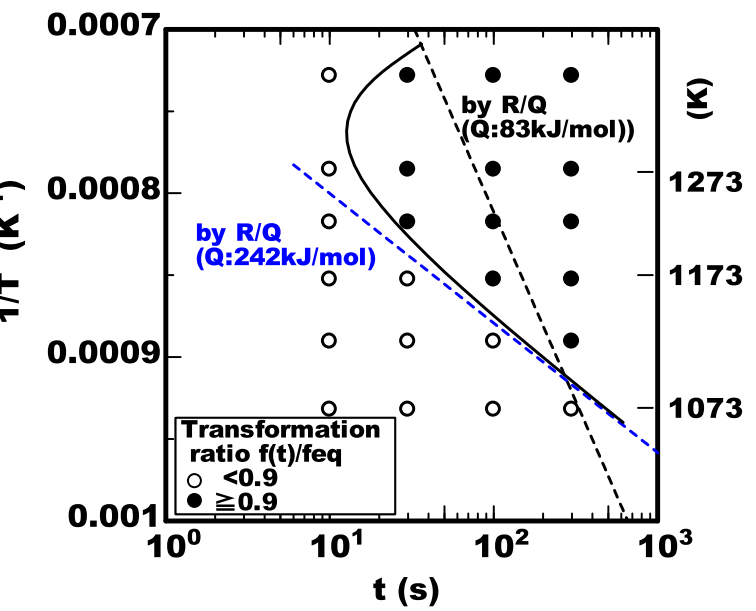

Fig. 7. Time-temperature-transformation curve with criteria of austenite phase friction of $60 \%$ and of progress ratio of transformation of 0.9 for $25 \mathrm{Cr}-7 \mathrm{Ni}-3 \mathrm{Mo}-2 \mathrm{~W}-0.3 \mathrm{~N}$ steel. (Online version in color.)

analysis are shown in Fig. 8. Those contents of Ni at the early stage of heating were close to the average contents within the steel that are $7 \%$ and $5 \%$ in the $25 \% \mathrm{Cr}$ and $22 \% \mathrm{Cr}$ steel respectively. In the later heating stage those increased. It is understood that the partitioning of $\mathrm{Ni}$ between the phases progressed with the growth of austenite phase for the equilibrium state during heating.

\section{Dominat Factor of Austenite Phase Growth}

\subsection{Validity of Growth Model Suggested}

As mentioned above the inclination of experimental TTP curve in the low temperature range was almost fit to the activation energy of diffusion of Ni. So that the dominant element for growth of austenite phase is considered to be $\mathrm{Ni}$. Therefore the value of diffusion coefficient of $\mathrm{Ni}$ was applied to that in Eq. (7). The optimum values of $k_{p 0}$ and $\Delta u_{m}$ shown in Table 2 were determined by the minimizing the difference between the experimental results and the calculated value by using Eq. (7). The values of the growth rate of austenite phase $k_{p}$ in each of the steels at various temperature were calculated applying the values of $k_{p 0}$ and $\Delta u_{m}$ in Table 2 to Eq. (7). The results were drawn as solid line within Fig. 6 at the same time. The calculated values of $k_{p}$ for whole of the steels had good fit to the experimental results. Consequently it was confirmed that the value of $k_{p}$ is described by applying the proper constants of $k_{p 0}$ and $\Delta u_{m}$ to Eq. (7) in the wide temperature range.

Because the value of $k_{p}$ is determined by just three constants of $\mathrm{T}_{\mathrm{eq}}, k_{p 0}$ and $\Delta u_{m}$, the investigation of the influence mechanism of alloying element the constants of $k_{p 0}$ and $\Delta u_{m}$ is conducted in the following. The energy barrier for the transformation of ferrite to austenite $\Delta u_{m}$ is described as shown in Eq. (11) by the change of enthalpy in the transformation $\Delta \mathrm{H}$ and interfacial energy $\sigma$ of the two phases. ${ }^{8)}$

$$
\Delta u_{m}=\left(16 \pi \mathrm{N} V^{2} \sigma^{3}\right) /\left[3\left(C_{p} \Delta H\right)^{2}\right]
$$

where $\mathrm{N}$ is Avogadro's number $\left(6.02 \times 10^{23}\right), \mathrm{V}$ is molar volume $\left(7.2 \times 10^{-6} \mathrm{~m}^{3} / \mathrm{mol}\right)$ and $C_{p}$ is the content of the dominant element. Figure 9 shows the calculated results of free energy change $\Delta \mathrm{G}$ in transformation using the thermodynamic data base in $25 \% \mathrm{Cr}-7 \% \mathrm{Ni}-3 \% \mathrm{Mo}-2 \% \mathrm{~W}-0.3 \% \mathrm{~N}$ steel and $22 \% \mathrm{Cr}-5 \% \mathrm{Ni}-3 \% \mathrm{Mo}-0.2 \% \mathrm{~N}$ steel. Because of the relation that the value of $\Delta \mathrm{G}$ is proportional to $C_{p} \Delta H(\Delta T /$ $\left.T_{e q}\right)$, the value of $C_{p} \Delta H$ is obtained as $68(\mathrm{~kJ} / \mathrm{mol})$ from the inclination of $\Delta \mathrm{G}$ to $\left(\Delta T / T_{e q}\right)$ in that calculated figure.

The value of interfacial energy $\sigma$ is unknown but reported as $0.1-0.4(\mathrm{~J} / \mathrm{mol})$. When that is assumed as $0.26(\mathrm{~J} / \mathrm{mol})$ 


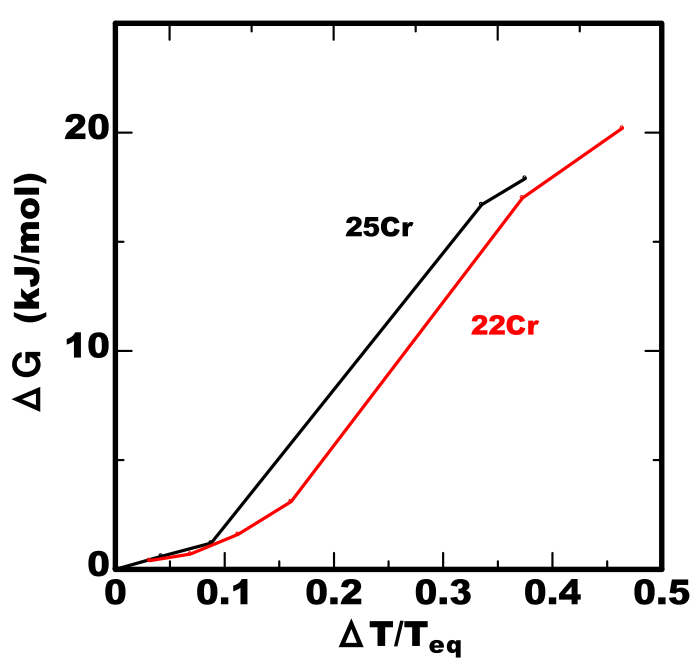

Fig. 9. Calculated driving force of transformation of ferrite to austenite phase. (Online version in color.)

the value of $\Delta u_{m}$ is calculated as $2000(\mathrm{~kJ} / \mathrm{mol})$. This value is close to the experimentally determined value shown in Table 2. In conclusion the dominant factors of $\Delta u_{m}$ are the change of enthalpy in the transformation $\Delta \mathrm{H}$ and interfacial energy $\sigma$ of the two phases. When the value of interfacial energy is clarified the value of $\Delta u_{m}$ can be obtained just from the calculation using Eq. (11) without experiment.

The other factor of $k_{p 0}$ is influenced by the density of number of austenite formation site $N_{0}$ as shown in Eq. (8). Assuming the formation site is on the edges of grain boundary in the Kelvin's fourteen planes hedron, the maximum number of the site $N_{0}$ is the following. ${ }^{9)}$

$$
N_{0}=6 \sqrt{2}(N / V)^{1 / 3} / R_{G}^{2}
$$

, where $R_{G}$ is the diameter of ferrite grain.

Assuming the values of $\Omega$ of $1.8, \mathrm{~L}$ of $10(\mu \mathrm{m})$ and $R_{G}$ of $100(\mu \mathrm{m})$ to Eqs. (8) and (12), the following value of $k_{p 0}$ is obtained.

$$
k_{p 0}=4.1 \times 10^{14} \quad\left(\mathrm{~s}^{-1}\right)
$$

This value is close to the experimental results shown in Table 2. The applied values of $\mathrm{L}$ and $R_{G}$ is not away from actual values. Therefore the validity of this model is considered to be supported by those results. Consequently it is understood that the dominant factors of $k_{p 0}$ are the super-saturation, thickness of the phase and the diameter of ferrite grain because the constant $\Omega$ is dependent on the super-saturation. The theoretical value of $k_{p 0}$ can be calculated with the Eqs. (2), (8) and (12).

Next the universality of the model proposed is investigated by evaluating the applicability for the reported data in the other work. ${ }^{3)}$ As shown in Fig. 10 those reported data of the growth rate of austenite phase had good fit with the calculated curve obtained by applying the values of constant in Table 2 to the Eq. (7). From the fact, a certain degree of universality of the model proposed for a steel consisting of different chemical composition was confirmed.

\subsection{Dominant Factors in Effect of Alloying Elements on Growth Rate}

The growth rate constant of austenite phase in the steel containing various levels of $\mathrm{Cr}, \mathrm{Ni}, \mathrm{W}$ and $\mathrm{N}$ was clarified

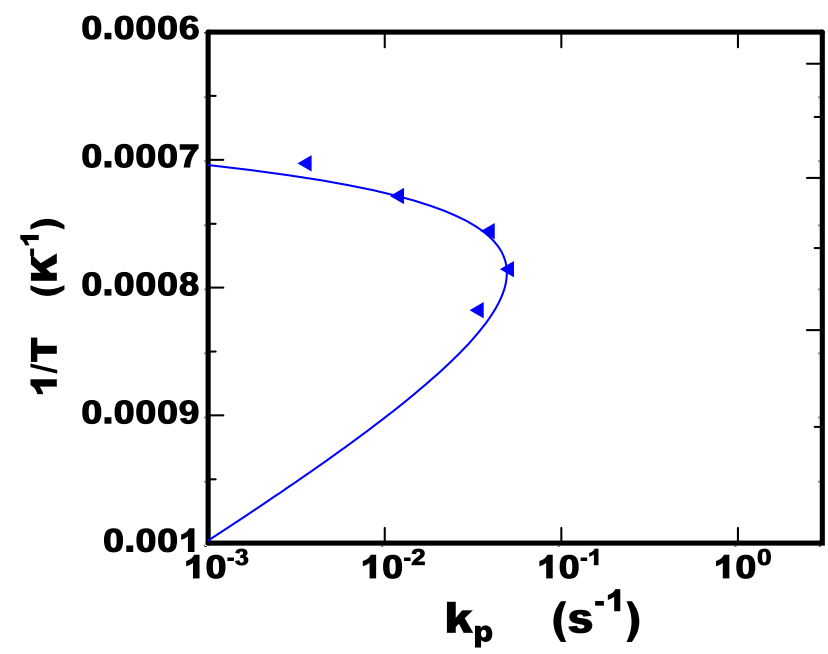

Fig. 10. Applicability of model of this work to data in reference work. (Online version in color.)

as shown in the above. The dominant factors regarding the effect of alloying elements on growth rate are considered in the following. At first it is easily understood that those alloying elements as an austenite or ferrite phase former influence on the upper limit temperature $\mathrm{T}_{\text {eq }}$ where the austenite phase is stable. That is calculated with thermodynamic data base. ${ }^{10)}$ Next those alloying elements did not almost influence on the value of the energy barrier for the transformation of ferrite to austenite $\Delta u_{m}$ as mentioned above. This fact explained that the change of enthalpy in the transformation and interfacial energy are almost same value among the steels used containing various levels of $\mathrm{Cr}, \mathrm{Ni}, \mathrm{W}$ and $\mathrm{N}$. The validity is supported by that $25 \% \mathrm{Cr}$ and $22 \% \mathrm{Cr}$ steel had the almost same value of the change of enthalpy in the transformation as already shown in Fig. 9. Regarding the constant $k_{p 0}$, the dominant factors have been mentioned in the above. The alloying elements influence on the value of super-saturation of those factors. The higher content of ferrite formation element such as $\mathrm{Cr}$ is, the more the term of super-saturation decreased resulting in reduction of the growth rate of austenite phase. On the contrary the effect to promote the austenite phase growth by the austenite formation element such as $\mathrm{Ni}$ or $\mathrm{N}$ is reflected on the increase of the term of super-saturation. The degree of influence can be calculated using thermodynamic data base as shown in Fig. 1. As results the dominant influence factor by the alloying elements are the upper limit temperature for the austenite stability $\mathrm{T}_{\mathrm{eq}}$ and the super-saturation. The both are calculated with thermodynamic data base. ${ }^{10)}$

\subsection{Influence Factor of Alloying Elements on Fraction of Austenite Phase}

The fraction of austenite phase $f(t)$ in a heating time $\mathrm{t}$ is obtained with the following equation based on Eqs. (7) and (1)

$$
f(t)=f_{e}\left(k_{p} t+f_{0} /\left(f_{e}-f_{0}\right)\right) /\left(1+k_{p} t+f_{0} /\left(f_{e}-f_{0}\right)\right) \ldots
$$

The calculated values are shown in Fig. 11 in comparison with the experimental data of the fraction of austenite phase. The both results had good fit therefore it was confirmed that it is possible to calculate the fraction of austenite by applying the values of the initial fraction $f_{0}$ and the equilibrium 
fraction $f_{e}$ to the model proposed. The values of $f_{0}$ and $f_{e}$ are important influence factors on the fraction of austenite phase in addition to the growth rate therefore the effect of alloying element of $\mathrm{Ni}$ and $\mathrm{N}$ on that fraction is investigated. The results at $1223 \mathrm{~K}$ are shown in Fig. 12. Especially by the increase of $\mathrm{N}$ in steels the value of $f_{0}$ remarkably increased. The interstitial element of $\mathrm{N}$ is considered to contribute to form much of austenite phase at the time quenched from $1653 \mathrm{~K}$ to $1223 \mathrm{~K}$ because of relatively much high diffusion rete comparing to that of substitution type elements therefore the higher value of $f_{0}$ is obtained in the steel containing higher $\mathrm{N}$. In the model in this work that contribution of $\mathrm{N}$ in stage $\mathrm{I}$ is reflected as the value of $f_{0}$ and in stage II the diffusion of $\mathrm{Ni}$ promotes the austenite growth with reduction of the gap between the values of $f_{0}$ and $f_{e}$. Therefore the increase of $\mathrm{N}$ in steel is effective to obtain a high fraction of austenite phase in short heating time due to the lowering the gap between $f_{0}$ and $f_{e}$. On the contrary in the steel containing low $\mathrm{N}$ it is not easy to form much austenite

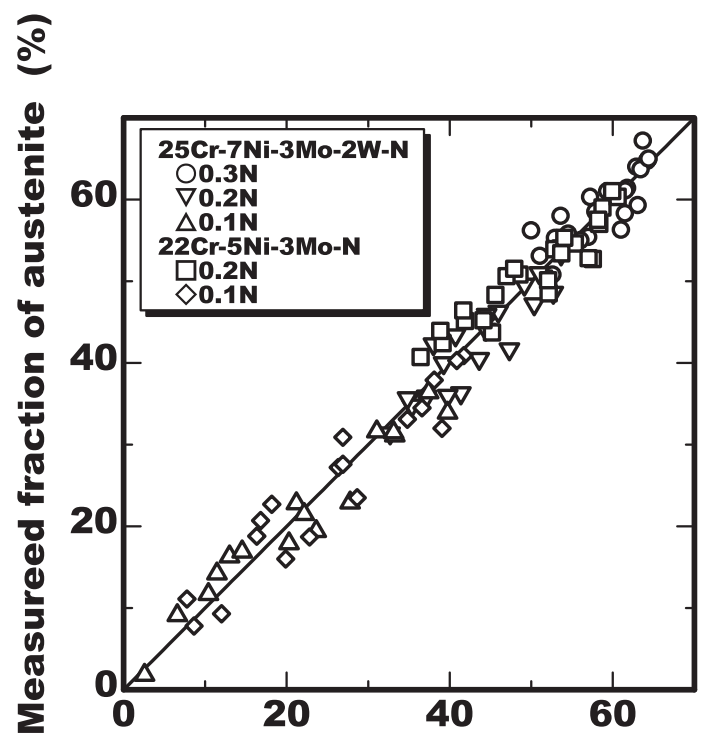

Calculated fraction of austenite $f(t)(\%)$

Fig. 11. Comparison of measured fraction of austenite and calculated values by model of this work.

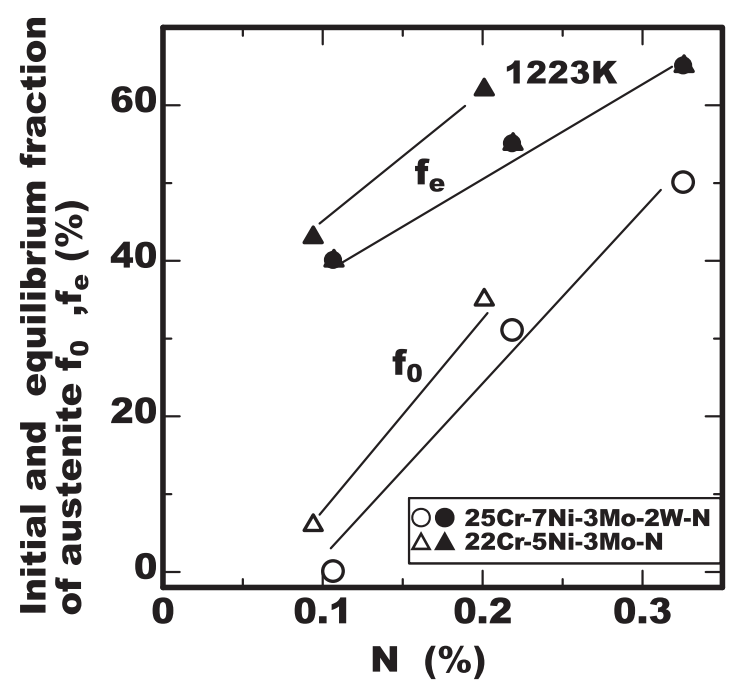

Fig. 12. Effect of $\mathrm{N}$ on initial and equilibrium fraction of austenite phase at $1223 \mathrm{~K}$. phase in short heating time due to the necessity of much of $\mathrm{Ni}$ diffusion of which rate is relatively low.

It is understood that the alloying elements control the growth of austenite phase by influencing the four factors of upper limit temperature for the austenite phase stability $\mathrm{T}_{\mathrm{eq}}$, the term of super-saturation, the equilibrium fraction $f_{e}$ and the initial fraction $f_{0}$ at the stage II. The prediction of the fraction of austenite phase in steel containing various chemical compositions in isothermal heating conditions can be obtained by using growth rate of austenite phase in the model proposed. The fraction of that in a continuously cooled portion such as the HAZ is calculated by the applying the additivity rule to the isothermal growth rate data as already reported.

The model proposed in this work focuses on the stage II. The values of three factors of $\mathrm{T}_{\mathrm{eq}}$, the term of supersaturation and $f_{e}$ in the three factors mentioned above are obtained using thermodynamic data base ${ }^{10)}$ but the value of $f_{0}$ is necessary to be determined by experiments except for the steels the value obviously assumed $f_{0}$ is equal to 0 , which have low driving force of austenite formation. It remains as a future subject to develop a model possible to determine the value of $f_{0}$ by easy calculation regarding the stage $\mathrm{I}$.

\section{Conclusion}

The following results were obtained by the investigation regarding the isothermal growth property of austenite phase from overcooled ferrite phase in the steel of $25 \% \mathrm{Cr}$ and $22 \% \mathrm{Cr}$ duplex stainless steels.

(1) The experimental results of the isothermal growth of austenite was according to the Austin-Rickett rule for the heating time.

(2) It was confirmed that the experimental results of the growth rate of austenite phase in steels containing various level of $\mathrm{Cr}, \mathrm{Ni}, \mathrm{W}$ and $\mathrm{N}$ is according to the equation in the proposed model that the disks grows just in the diameter direction with the number of that disk according to Boltzmann distribution.

(3) From the consideration of the model, it is was concluded that the dominant factors to control the fraction of austenite phase formed from overcooled ferrite are the four factors of upper limit temperature for austenite phase stability, super-saturation, the equilibrium fraction and the initial fraction of austenite phase in the isothermal heating.

\section{REFERENCES}

1) R. N. Gunn: Duplex Stainless Steel, Abinton Publishing, Cambridge, (1997), 110 .

2) H. Liou, R. Hsieh and W. Tsai: Corros. Sci., 44 (2002), 2841.

3) Y. Nakao, K. Nishimoto and S. Inoue: J. Jpn. Weld. Soc., 50 (1981), 514 (in Japanese).

4) Y. Tanabe, K. Onishi, T. Ogura, K. Saida, K. Nishimoto and Y. Oikawa: Proc. National Meeting of JWS, Vol. 95, JWS, Tokyo, (2014), 230 (in Japanese).

5) Y. Nakao, K. Nishimoto and S. Inoue: J. Jpn. Weld. Soc., 50 (1981), 1107 (in Japanese).

6) K. Yasuda, R. N. Gunn and T. G. Gooch: Q. J. Jpn. Weld. Soc., 20 (2002), 68 (in Japanese).

7) M. Enomoto: Japan Institute of Metals and Materials Seminar, Base and Application of Phase Diagram and Transformation in Material Science, JIM, Sendai, (1992), 73 (in Japanese).

8) T. Nishizawa, trans. by K. Ishida: Thermodynamics of Microstructures, ASM International, Almere, The Netherlands, (2008), 91.

9) M. Umemoto and I. Tamura: J. Jpn. Soc. Heat Treat., 24 (1984), 334 (in Japanese).

10) Thermo-Calc Software: Thermo-Calc Software - Computational Materials Engineering, http://www.thermo-calc.com, (accessed 2018-10-15). 